\title{
THE ELECTROCARDIOGRAM ON THE FIRST DAY OF LIFE
}

\author{
BY \\ I. KESSEL \\ From the Department of Padiatrics, University of the Witwatersrand, and the Transvaal Memorial Hospital \\ for Children, Johannesburg, South Africa \\ Received June 10, 1953
}

Electrocardiography in the early new-born period has not been very extensively studied, although many reports have been published of cardiographic patterns in older children. With the rapid development of cardiac surgery, it is important to standardize normal cardiographic tracings to aid in the accurate diagnosis of congenital cardiac lesions as early as possible.

Nicolai and Funaro (1908) recorded the first study of electrocardiography in children. They noted the frequent presence of a deep S wave in lead 1. In 1915, Krumbhaar and Jenks commented on deep $Q$ waves in children's cardiograms. Master et al. (1935) reported the first investigation of chest lead cardiography in children, and noted that in very young children the $T$ wave frequently remained negative as far over the chest as the apex. Robinow et al. (1936) commented that in children 14 years of age, the $T$ wave became similar to the normal adult. Groedel and Miller (1944) investigated electrocardiograms in the new-born infant, and observed a right heart pattern in chest leads 1 and 2, and left patterns in chest leads 5 and 6 . Battro and Mendy (1946) investigated three age-groups of children, including a group 0-2 years using standard leads, unipolar extremity leads and six unipolar chest leads: in the youngest age-group, they noted a Rs pattern in V1, and frequent negative T waves up to V6. Schaffer et al. (1950) studied unipolar electrocardiography in the normal new born and noted the negative $T$ waves in right-sided chest leads and upright $T$ waves in left chest leads.

The study presented here is recorded to add to present knowledge of electrocardiography in the immediate new-born period. Tracings were taken in 15 normal new-born Bantu infants within 24 hours of birth.

\section{METHOD AND Results}

The group of 15 normal new-born Bantu infants comprised 9 boys and 6 girls. The youngest infant was $2 \frac{3}{4}$ hours old and the oldest was 21 hours (Table I). They were all submitted to a thorough clinical examination. The presence of any abnormality excluded them from this investigation. The birth weights varied from the highest level of $4 \mathrm{~kg}$. to the lowest of $2.5 \mathrm{~kg}$. The tracings were recorded using a Sanborn direct-writing electrocardiograph. They were taken with the infant recumbent and quiet and the following leads recorded: standard leads I, II, and III, leads aVR, aVL, aVF, V1 to V6, VS (sternal-fourth interspace level), and two right-sided chest leads in the fourth interspace. The tracings were studied from the following aspects: rate and rhythm, position, $P-R$ interval, and general observations on the QRS, $P$, and T components. A typical electrocardiogram of a new-born infant is shown in Fig. 1.

The heart rate varied from the most rapid of 150 a minute in four cases, to the slowest rate of 100 a minute, in one case. The rate bore no relationship to the birth weight or the time after birth. There was normal sinus rhythm in all the tracings.

Position of the heart. All the tracings showed a negative deflection rS pattern in lead aVL and a positive deflection $\mathrm{qR}$ pattern in lead aVF. All these patients showed a vertical position of the heart.

$P-R$ interval. The P-R interval varied from the longest period of $0.12 \mathrm{sec}$. in three cases, to the shortest of $0.08 \mathrm{sec}$. in four cases. In the remaining eight cases the duration of the $P-R$ interval was $0.1 \mathrm{sec}$. There 
was no relationship to the heart rate. The shortest interval of 0.08 sec. occurred both at a rate of 115 a minute and at 150 a minute.

$P$ wave. The $\mathbf{P}$ wave was inverted in every tracing of lead aVR. It was inverted in one tracing of lead III and in two tracings of lead aVL. It was always upright in leads aVF and VS. Its amplitude was constantly highest in the sternal lead.

$Q$ wave. This was present in every tracing of standard lead III and in eight cases of lead II. It was constantly present in lead aVF.

TABLE I

Heart Rate and P-R Interval in the First 24 Hours of Life

\begin{tabular}{c|c|c|c|c}
\hline Case & Sex & $\begin{array}{c}\text { Age } \\
\text { (hours) }\end{array}$ & $\begin{array}{c}\text { Rate } \\
\text { a minute }\end{array}$ & $\begin{array}{c}\text { P-R interval } \\
\text { in seconds }\end{array}$ \\
\hline 1 & Female & 12 & 115 & $0 \cdot 10$ \\
2 & Female & $2 \frac{3}{4}$ & 136 & $0 \cdot 10$ \\
3 & Female & 8 & 115 & $0 \cdot 12$ \\
4 & Female & $3 \frac{3}{4}$ & 100 & $0 \cdot 12$ \\
5 & Female & 10 & 115 & $0 \cdot 10$ \\
6 & Female & $3 \frac{1}{2}$ & 125 & $0 \cdot 08$ \\
7 & Male & 21 & 150 & $0 \cdot 10$ \\
8 & Male & 10 & 115 & $0 \cdot 08$ \\
9 & Male & 11 & 150 & $0 \cdot 08$ \\
10 & Male & $20 \frac{3}{3}$ & 150 & $0 \cdot 08$ \\
11 & Male & $6 \frac{1}{2}$ & 110 & $0 \cdot 10$ \\
12 & Male & 10 & 136 & $0 \cdot 10$ \\
13 & Male & $8 \frac{1}{2}$ & 115 & $0 \cdot 12$ \\
14 & Male & 18 & 150 & $0 \cdot 10$ \\
15 & Male & 13 & 115 & $0 \cdot 10$ \\
\hline
\end{tabular}

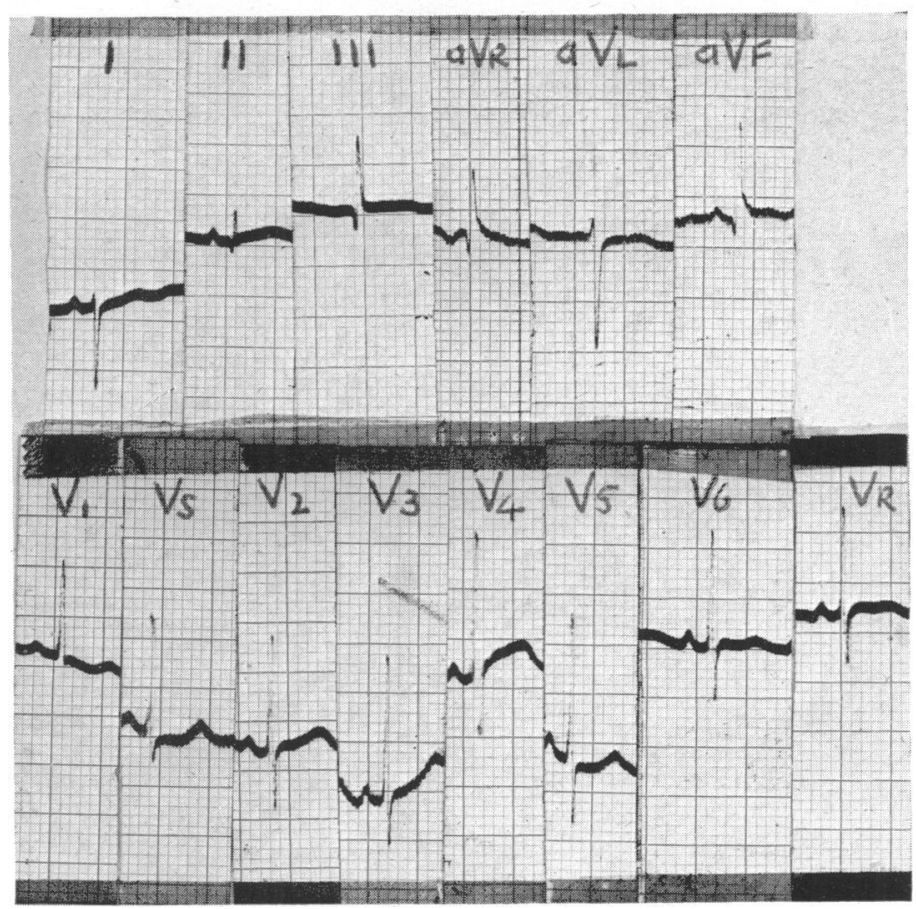

Fig. 1.-Electrocardiogram of a normal infant recorded within 24 hours of birth. 
$T$ wave. The $T$ wave was inverted in all tracings in lead aVR. It was also inverted in three cases in lead III, and twice in lead II. In two tracings, an upright $T$ wave became negative on passing from the right side of the chest to the left, a similar finding to that recorded by Furman and Halloran (1951). In one tracing, negative $T$ waves on the right side of the chest became positive on passing to the left.

QRS pattern. These patterns in leads V1 to V6 varied except that the positive and negative deflections were constantly of approximately equal magnitude in leads V3 or V4. In the right-sided chest leads a large $\mathbf{R}$ wave was constantly present.

\section{Discussion}

In the immediate new-torn period, the rhythm, position of the heart, and P-R interval appear to be fairly constant. This small series illustrates the variability of the $T$ wave in this age-group. In two tracings the S-T segment was depressed in V2. Furman and Halloran (1951) also commented on this finding. The heart of the neonate differs from the adult in the much greater surface area of the right ventricle being in contact with the thin anterior chest wall. Richman and Master (1951) suggested the different ratio of left and right ventricular muscle mass in childhood and in the adult to explain the differing electrocardiograms. The rate varied between 100 and 150 a minute.

\section{SUMMARY}

Electrocardiograms were taken in a series of 15 normal new-born Bantu infants within 24 hours of their birth. Nine were boys and six girls. Standard leads and the unipolar extremity and chest leads were employed. The heart was always vertical in position. The rate varied from the most rapid at 150 a minute to the slowest at 100 a minute. Normal sinus rhythm was present in all the tracings. The P-R intervals varied between 0.12 second and 0.08 second, bearing no relationship to the heart rate. Certain special features of the various components of the electrocardiogram in the new-born have been described. In two cases, an upright $T$ wave became negative on passing from the right side of the chest to the left, and once a negative $T$ wave on the right side became positive on passing to the left. The QRS patterns in the chest leads varied, transition occurring between V3 and V4. A large R wave was always present in the right-sided chest leads.

I wish to thank Dr. Seymour Heymann, Head of the Department of Pædiatrics, University of the Witwatersrand, for his advice and criticism. I must also thank Dr. Eric Kahn for facilities offered and the Obstetrics Department, Baragwanath Hospital, for providing the patients for study.

\section{REFERENCES}

Battro, A., and Mendy, J. C. (1946). Arch. Intern. Med., 78, 31. Furman, R. A., and Halloran, W. R. (1951). J. Pediat., 39, 307. Groedel, F. M., and Miller, M. (1944). Exper. Med. Surg., 2, 110. Krumbhaar, E. B., and Jenks, H. H. (1915). Heart, 6, 189.

Master, A. M., Dack, S., and Jaffe, H. L. (1935). Proc. Soc. Exper. Biol. Med., 32, 1529.

Nicolai, G. F., and Funaro (1908). Zentralb. F. Physiol., 22, 58.

Richman, B., and Master, A. M. (1951). Amer. Heart J., 41, 687.

Robinow, M., Katz, L. N., and Bohning, A. (1936). Amer. Heart J., 12, 88.

Schaffer, A. I., Burstein, J., Marcia, A. V., Barenburg, P. L., and Stillman, N. (1950). Amer. Heart J., $39,588$. 